J. Sustain. Wireless Syst.

Vol.01/ No. 03

Pages: 176-188

http://irojournals.com/irosws/

DOI: https://doi.org/10.36548/jsws.2019.3.004

\title{
REVIEW ON UBIQUITOUS CLOUDS AND PERSONAL MOBILE NETWORKS
}

\author{
Dr. Samuel Manoharan, \\ Professor, Department of Electronics, \\ Bharathiyar College of Engineering and Technology, \\ Thiruvettakudy, Karaikal, India. \\ Email id: jsamuel@bcetedu.in
}

\begin{abstract}
The cloud that frame the future of the computing has become more popular nowadays due to its numerous attractive benefits such as self-servicing, resource-pooling, elasticity, improved-scalability, resilience , and operational and migration flexibility. This server-client model with the pay per usage facility is described by the NIST as the enabling, on-demand, convenient-network access, with shared pool of computing resources that are provided swiftly with the minimal efforts of management and interactions. The paper gives a brief review on the continuous cloud computing services, explaining its ubiquity, and then proceeds with the usefulness of the cloud services in the personal mobile network, that could enable an enhancement in the performance of the personal mobile network in the future.
\end{abstract}

Keywords: Ubiquitous cloud, deploying models of cloud, services of cloud, cloud advantages, personal mobile networks

\section{Introduction}

The cloud computing that has become a promising paradigm for providing of service on pay-per-use, has gained an immense popularity due to its service provisioning that is efficient, flexible, elastic and the agile. The cloud computing by its service provisioning enables the user to work on a software without purchasing it, so the cloud enables the cost-cutting in terms of software purchase and maintenance by renewing, the cloud service even provides the users with the, infrastructure, platform, storage, security and the workflow as service, bringing down the investment cost and increasing the productivity, thus ensuring a strategic edge for the business. The seamless service provisioning of the cloud has made possible the completion of the work from anywhere, at any time, by any people. The concept of the cloud computing was developed to ensures the resource reuse in the IT, the development and hosting of applications that are complex, and the expansion of the computation power and more other services on pay-as -you -go. The characteristics of the cloud that is adopted from the different traditional computing

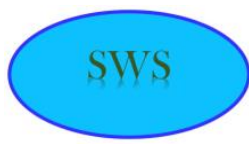


J. Sustain. Wireless Syst.

Vol.01/ No. 03

Pages: 176-188

http://irojournals.com/irosws/

DOI: https://doi.org/10.36548/jsws.2019.3.004

technologies such as, cluster, grid, utility and distributed allows the user to enjoy the benefits of the technologies without having an expertise knowledge on the them. Based on the deployments of the cloud, the cloud be categorized as public, private, hybrid and community cloud. The public cloud, offering services with the shared resources has its entire service mounted on the cloud company, without any facility for the external control by the user. This ensures better performance for its clients. The private cloud are more preferred than the public, as they provide with remote or an onsite cloud infrastructure that exclusively belongs to a person or an organization. The private cloud includes the benefits of the public cloud and offers even better performance with the security enhancements. The hybrid cloud includes both the private and the public cloud services offering an expanded flexible operation with the greater options for the data deploying. The community cloud enables the cloud infrastructure to be shared within specific community such as group of individuals or organizations who are related with same concerns. The service provisioning of the cloud makes them potential suitable for the emerging applications and service that are related to a wide area. The service provisioning of the cloud is more opted for and yet to be opted by the concerns ranging from small to large scale as it provides with the pay as you use model with self-service without human intervention, but with cost-reduction, broader network access, scalability, reliability, maximum resource utilization, ability of re-configuring, resource-pooling and elasticity for a multiple number of users within the same span. From this client server model of cloud computing with the self-service and pay on use, the individual or the organizations is relaxed as the cloud is responsible for the complete maintenance that includes the updation of the applications, operating systems, networking, storage, physical-server and antivirus. So the cloud as mentioned above is more promising and beneficial for its clients with greater accessibility of network which makes the cloud ubiquitous. The table 1 gives the deploying models of the cloud that makes it ubiquitous.

So the paper is review the ubiquity cloud computing and it's enabling characteristics and services that could be useful in enhancing the performance of the personal mobile network.

The paper is organized with the 2 explaining the ubiquity of the cloud services from the survey conducted, 3 . The details carrying the information of the personal mobile network, 4 improvements that could be scoped in the personal mobile network by the ubiquitous cloud services and 5.conclusion.

\section{Ubiquitous Cloud services}

The enabling cloud computing with the key characteristics offering high reliableness, with improved level of the scalability and managing capability are categorized based on their service provisioning as software, platform, storage, recovery, security, and work flow. The table 2 presented below gives the detailed description of the services

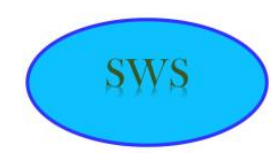


J. Sustain. Wireless Syst.

Vol.01/ No. 03

Pages: 176-188

http://irojournals.com/irosws/

DOI: https://doi.org/10.36548/jsws.2019.3.004

provided by the cloud that paves way for the agility, cost-reduction, maintenance, multi-tenancy with device and the location independence. This anywhere, anytime, anybody access of the cloud makes it ubiquitous and popular among enlarged and wide range of applications.

\begin{tabular}{|c|c|c|c|}
\hline Deploying models & Governed By & Used by & Advantages \\
\hline Public & $\begin{array}{l}\text { Cloud service- } \\
\text { provider }\end{array}$ & $\begin{array}{l}\text { Common people, } \\
\text { industrial } \\
\text { applications, } \\
\text { organizations etc. }\end{array}$ & $\begin{array}{l}\text { Economical offering medium } \\
\text { level of security.[12],[33],[35] }\end{array}$ \\
\hline Private & $\begin{array}{l}\text { Individual } \\
\text { organization } \\
\text { Group of people }\end{array}$ & $\begin{array}{l}\text { individual } \\
\text { organizations, or } \\
\text { industries }\end{array}$ & $\begin{array}{l}\text { Economical, offers high level } \\
\text { of security, [2],[35] }\end{array}$ \\
\hline Hybrid & $\begin{array}{l}\text { Common people and } \\
\text { Organization }\end{array}$ & $\begin{array}{l}\text { Common people and } \\
\text { Organization }\end{array}$ & $\begin{array}{l}\text { Enables aggregation, } \\
\text { integration and customization } \\
\text { with other cloud service, offers } \\
\text { medium level of security, } \\
\text { expands the capability of the } \\
\text { cloud services,[35],[48] }\end{array}$ \\
\hline Community & $\begin{array}{l}\text { Multiple } \\
\text { organizations or } \\
\text { Cloud service- } \\
\text { provider }\end{array}$ & $\begin{array}{l}\text { Group of } \\
\text { Organization and } \\
\text { industries with same } \\
\text { concern based on the } \\
\text { policy and security. }\end{array}$ & $\begin{array}{l}\text { Improvises the automation, } \\
\text { productivity, functionality and } \\
\text { offers enhancement in } \\
\text { features.[35],[48] }\end{array}$ \\
\hline Multiple & $\begin{array}{l}\text { Multiple Cloud } \\
\text { service-provider }\end{array}$ & $\begin{array}{l}\text { Single organization } \\
\text { or common people } \\
\text { or multiple } \\
\text { organizations and } \\
\text { industries }\end{array}$ & $\begin{array}{l}\text { Economical, offers reliableness, } \\
\text { operational-flexibility, high } \\
\text { performance and security } \\
\text { against attacks. [28] }\end{array}$ \\
\hline Distributed & $\begin{array}{l}\text { Cloud service- } \\
\text { provider }\end{array}$ & $\begin{array}{l}\text { industrial } \\
\text { applications, } \\
\text { organizations etc. }\end{array}$ & $\begin{array}{l}\text { High quality- real time cloud } \\
\text { service, reduced network } \\
\text { latency and Congestion [44] }\end{array}$ \\
\hline Big-Data & $\begin{array}{l}\text { Cloud service- } \\
\text { provider }\end{array}$ & $\begin{array}{l}\text { Large } \quad-\text { scale } \\
\text { industrial } \\
\text { applications }\end{array}$ & $\begin{array}{l}\text { Offers Better analysis, data } \\
\text { acquisition, } \\
\text { environment.[42],[20],[10],[36] }\end{array}$ \\
\hline $\mathrm{HPC}$ & $\begin{array}{l}\text { Cloud service- } \\
\text { provider }\end{array}$ & $\begin{array}{ll}\text { Applications } & \\
\text { requiring } & \text { high } \\
\text { performance } & \text { like } \\
\text { (seismic } & \text { data } \\
\text { processing) } & \\
\end{array}$ & $\begin{array}{l}\text { Improved computing } \\
\text { capabilities, offers parallel } \\
\text { processing. [38] }\end{array}$ \\
\hline
\end{tabular}


J. Sustain. Wireless Syst.

Vol.01/ No. 03

Pages: 176-188

http://irojournals.com/irosws/

DOI: https://doi.org/10.36548/jsws.2019.3.004

Table.1 Deploying Models of Cloud

The table 2 below explains the different service of the cloud that paves way for its ubiquity,

The key characteristics and the service provisioning of the cloud given above states the reason for the cloud popularity among various application making it ubiquitous in the accessing, storing, protecting and monitoring of the data without the need for the external, external storage, security, recovery mechanism, software, platform and maintenance.

\section{Personal Mobile Network}

The Personal mobile network, is decentralized network that is framed on the fly with the nearby available devices using the mobile network, for the personal use of the individual, or group of individuals. The device connected in the network might be homogenous or heterogeneous, for example the network could be framed either using the laptop or the mobile phones that are nearby. The setting up of the personal mobile network, is easy as they are set up considering the mobile phones or the laptops as their nodes and share information's by tethering, here the nodes

\begin{tabular}{|l|l|l|l|}
\hline Cloud Services & \multicolumn{1}{|c|}{ Uses } & \multicolumn{1}{c|}{ Applications } & \multicolumn{1}{c|}{ Advantages } \\
\hline Software as Service & $\begin{array}{l}\text { Provides access to the client } \\
\text { on the application software, } \\
\text { operating system and other } \\
\text { resources, and takes care of } \\
\text { their maintenance. }\end{array}$ & $\begin{array}{l}\text { Used in the wide range of } \\
\text { areas that require the } \\
\text { application software and } \\
\text { operating system. (from } \\
\text { home to industries) }\end{array}$ & $\begin{array}{l}\text { Offers swift scalability, } \\
\text { ubiquitous accessibility, } \\
\text { and maintenance } \\
\text { decreases the software } \\
\text { privacy, }\end{array}$ \\
\hline Platform as service & $\begin{array}{l}\text { Enables the clients to } \\
\text { build, manage, and execute } \\
\text { the applications eluding the } \\
\text { complexity and need for } \\
\text { building and maintaining. }\end{array}$ & $\begin{array}{l}\text { Used in a wide range of } \\
\text { government, public and } \\
\text { private enterprises, } \\
\text { organization and industries }\end{array}$ & $\begin{array}{l}\text { Reduced expenditure, lead } \\
\text { times, and skill } \\
\text { requirements, capable of } \\
\text { adding new users at ease. } \\
\text { Makes the maintenance and } \\
\text { enhancements easier, } \\
\text { higher level programming } \\
\text { capability eluding } \\
\text { complexity, }\end{array}$ \\
\hline Storage as service & $\begin{array}{l}\text { Conceals the data or the } \\
\text { information in a hardware } \\
\text { in a remote location that is } \\
\text { accessible through any } \\
\text { device. }\end{array}$ & $\begin{array}{l}\text { Used mainly in medical } \\
\text { industries and the } \\
\text { organization that handle } \\
\text { large data-flow and needs } \\
\text { more hardware for storing } \\
\text { of information's }\end{array}$ & $\begin{array}{l}\text { Offers Easy access, storing, } \\
\text { retrieving and sharing, } \\
\text { offers scalable service, data } \\
\text { backups and are very } \\
\text { economical }\end{array}$ \\
\hline Recovery as service & $\begin{array}{l}\text { It provides the protection } \\
\text { for the data or the } \\
\text { information by back-up } \\
\text { and restore from being } \\
\text { destroyed during the }\end{array}$ & $\begin{array}{l}\text { Used mainly in area or the } \\
\text { industries or organizations } \\
\text { liable to frequent, natural } \\
\text { or human disasters. }\end{array}$ & $\begin{array}{l}\text { Prevents permanent loss, } \\
\text { cost-effective, flexible and } \\
\text { allows faster recovery with } \\
\text { accuracy maintenance }\end{array}$ \\
\hline
\end{tabular}

ISSN: 2582-3167 (online)

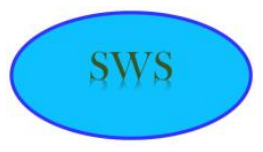


J. Sustain. Wireless Syst.

Vol.01/ No. 03

Pages: 176-188

http://irojournals.com/irosws/

DOI: https://doi.org/10.36548/jsws.2019.3.004

\begin{tabular}{|c|c|c|c|}
\hline & $\begin{array}{l}\text { natural or the human } \\
\text { disaster. }\end{array}$ & & \\
\hline Security as service & $\begin{array}{l}\text { The different security } \\
\text { provisioning are clubbed in } \\
\text { the cloud and provided for } \\
\text { each information stored in } \\
\text { it, the application } \\
\text { developed, the information } \\
\text { stored and the process done } \\
\text { are protected from } \\
\text { mishandling with the } \\
\text { security provisions of the } \\
\text { cloud }\end{array}$ & $\begin{array}{l}\text { Used by the government, } \\
\text { industries, organizations, } \\
\text { banks and the public who } \\
\text { scope for the improved } \\
\text { security service to protect } \\
\text { the information from } \\
\text { hacker. }\end{array}$ & $\begin{array}{l}\text { Economical, consistent } \\
\text { protection, greater security, } \\
\text { faster service provisioning, }\end{array}$ \\
\hline Work-Flow as service & $\begin{array}{l}\text { The custom workflow are } \\
\text { incorporated into the cloud } \\
\text { computing to enhance its } \\
\text { capabilities }\end{array}$ & $\begin{array}{l}\text { Used in government and } \\
\text { private industries and } \\
\text { scientific applications, }\end{array}$ & $\begin{array}{l}\text { Improves efficiency, saves } \\
\text { production time and cost, } \\
\text { enhances the quality, } \\
\text { flexibility in resource } \\
\text { allocation and scalability, } \\
\text { Reduces the } \\
\text { communication loss. }\end{array}$ \\
\hline Network as service & $\begin{array}{l}\text { This provides the network } \\
\text { infrastructure as service } \\
\text { such as, WAN and } \\
\text { datacenter connectivity, the } \\
\text { bandwidth on demand, and } \\
\text { takes care of the traffic and } \\
\text { the congestion status. }\end{array}$ & $\begin{array}{l}\text { Used in the private } \\
\text { network that utilizes the } \\
\text { network infrastructure } \\
\text { service provided by the } \\
\text { cloud. }\end{array}$ & $\begin{array}{l}\text { Reduced maintenance cost, } \\
\text { guaranteed connectivity, } \\
\text { easy setup, management } \\
\text { and maintenance. }\end{array}$ \\
\hline
\end{tabular}

Table 2. Service Provisioning's of Cloud

acting as modem makes the transmission possible through internet sharing. The personal mobile network more or less resemble the heterogeneous adhoc network[41] that frames its own network using the available nearby devices usually termed as nodes in the adhoc network. The personal mobile network though facilitated with the advantages of easy setup, spontaneous sharing of information's within a small group of people, suffers from major problems and incur challenges same as that of the adhoc network networks [47] such as storage, for the application that necessitates huge storage capacity and [50] security as the network framed could be liable of being hacked. They also suffer from various other problems such as mobility, privacy, short battery span and so on. The section below include the possible remedies for the personal mobile network through the cloud services. Fig 1 shows the issues suffered by the personal mobile network. 
J. Sustain. Wireless Syst.

Vol.01/ No. 03

Pages: 176-188

http://irojournals.com/irosws/

DOI: https://doi.org/10.36548/jsws.2019.3.004

\section{Ubiquitous Cloud for Personal Mobile Network (PMC)}

The Service provisioning of the cloud listed in the table 2 shows the ubiquity trend of the cloud service provisioning. The different services that were rendered by the cloud such as storage, security, recovery, workflow, resource allocation, could be utilized to enrich the personal mobile network in terms of the storage, security, resource allocation and energy saving serving as the remedy for the problem arising in the personal mobile networks due to their limitations in the storage, processing and the battery. From the survey proceeded for the review, the cloud services ensures the remedies for the issues in the personal mobile network, the integration of the personal mobile network to the cloud that offers a ubiquitous service would enhance the performance of the personal mobile network thus providing a quality service.

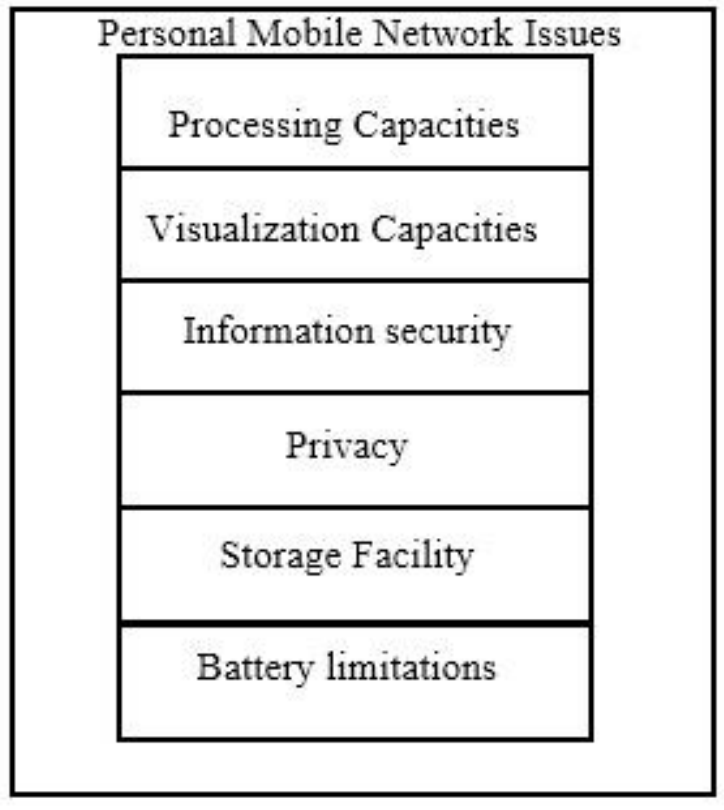

Fig 1 Personal Mobile Network Issues

\subsection{Improving the Storage capabilities of PMC}

The personal mobile network that suffers from the shortage of the storage for the applications that require high storage capabilities could be overcome by adopting cloud environment that offers storage as service, the researches 
J. Sustain. Wireless Syst.

Vol.01/ No. 03

Pages: 176-188

http://irojournals.com/irosws/

DOI: https://doi.org/10.36548/jsws.2019.3.004

done on the storage service for the cloud by Somula, et al [6] describes the cloud computing storage service rendering for the mobile networks by framing cloudlets, the storage Lee et al [21] speaks about the inabilities of the mobile networks in terms of storage as they process and store huge amount of data and the storage augmentation through the cloud services. The high definition pictures captured and the videos downloaded could as been saved in the cloud and retrieved whenever necessary. Yang, et al [43] describes the intention of the users to adopt the cloud storage as service, and the fascinating feature of the cloud that attracts more users towards the cloud storage as service, Goode et al [45] and the Aminzadeh et al [45] also details the research explored on the benefits of cloud storage as service for the mobile networks. The personal mobile network for the purpose of storage augmentation could incorporate the cloud service, to enjoy the storage service provided by cloud and overcome the limitations of the personal mobile network in terms of the storage. The storage facilities of the cloud also act as a backup for the information on the times of disaster that is natural or man-made.

\subsection{Improving Processing In-Capabilities of the PMC}

The researches proceeded on the cloud services by Alkhalaileh et al [7] and Koubâa et al [19] shows the efficient management and the resource allocation services provided by the cloud to enhance the processing capabilities in the application used. The personal mobile network, that is often reframed due to is mobile nature can improve its processing capabilities by adopting the cloud service, the researches proceeded by the Toosi et al [25] and Meneses et al [30] gives details of the cloud communications with extended connectivity, the bandwidth on demand and the reduced communication loss for the mobile networks that handle increasingly large number of connected user components, this ensures that the personal mobile network also would experience the same when adapted to the cloud environment. The handling of the large number of user's components would be easy, with negligible connection and the communication loss, and full utilization of the bandwidth of the cloud on-demand.

\subsection{Improving Security and Privacy of the PMC}

The security and the privacy issue of the personal mobile network can be improved using the cloud services, the security provisioning of the cloud services explained Rath et al [5] describes the security provisioning of the mobile networks through the authentication eluding the misuse of the information's, the security features added to the mobile networks stops the unnecessary utilization of the network details, by the unauthorized users. Kaur, et al [11], Colman-Meixner et al [14] and Cheng gives the details of the security and the privacy preserving's of the cloud services in various applications, the security and the privacy preserving's adapted in terms of key generation, 
J. Sustain. Wireless Syst.

Vol.01/ No. 03

Pages: 176-188

http://irojournals.com/irosws/

DOI: https://doi.org/10.36548/jsws.2019.3.004

authentication and encryption and decryption from the cloud could be incorporated in the personal mobile network, to elude the mishandling of the information's.

\subsection{The Efficiency in Terms of Cost and Energy}

The cloud doing a fascinating job providing with the service of storage, recovery, security, resource allocation and so are also efficient in terms of the cost [33] and energy, [34], the efficiency, the pay as you go concept of the cloud requests the pay only when the resources are used. Some cloud based services that demands the pay on the hourly bases allows the users to enjoy all the service for the time period on the limited pay mentioned. Its speedy processing capabilities enables the energy conservation, improving the efficiency of the client. So this makes the cloud more attractive and the personal mobile network incorporating the cloud would improve in the terms of storage, processing, battery with security for the information's the table 3 below gives the overview of the few remedies presented for the personal mobile network by cloud for its issues

\begin{tabular}{|l|l|l|}
\hline \multicolumn{1}{|c|}{ Issues of Personal Mobile Network } & \multicolumn{1}{|c|}{ Cloud services } & \multicolumn{1}{|c|}{ Remedies } \\
\hline Storage limitations & $\begin{array}{l}\text { Storage provisions } \\
{[6]_{,}[21]_{,}[43]_{,[45],[49]}}\end{array}$ & $\begin{array}{l}\text { Augmented storage, making it capable } \\
\text { of handling memory-intensive } \\
\text { applications. }\end{array}$ \\
\hline Processing incapability's & $\begin{array}{l}\text { Resource allocation, [7],[19], network } \\
\text { connectivity [25], [30], [37],[38] }\end{array}$ & $\begin{array}{l}\text { Improves the processing capabilities of } \\
\text { the PMC in terms of resource } \\
\text { allocation, bandwidth utilization, } \\
\text { communication and connectivity. }\end{array}$ \\
\hline Security and privacy & $\begin{array}{l}\text { Security provisioning' and privacy } \\
\text { preserving's [5],[11],[14],[15],[23],[21] }\end{array}$ & $\begin{array}{l}\text { Would provide protection for the PMC } \\
\text { from the mishandlings and hacking }\end{array}$ \\
\hline Energy and cost efficiency & $\begin{array}{l}\text { Cost-awareness [33], the energy- } \\
\text { awareness [34] and the speedy } \\
\text { processing [9] of cloud services }\end{array}$ & $\begin{array}{l}\text { Would enable the PMC to have an } \\
\text { efficiency in terms of cost and the } \\
\text { energy consumption }\end{array}$ \\
\hline
\end{tabular}

Table.3 Remedies for the personal mobile network Issues

The solutions obtained from the cloud survey performed, for its services and the deploying models proving its ubiquity, on various other applications could be used in the personal mobile network to improve its performance overcoming the issues related to the storage, processing, security and battery, the paper presents the possible solutions that could improve the personal mobile network from the survey conducted. The development of the personal mobile network with the inclusion of the solutions could be proceeded as the future enhancement. 
J. Sustain. Wireless Syst.

Vol.01/ No. 03

Pages: 176-188

http://irojournals.com/irosws/

DOI: https://doi.org/10.36548/jsws.2019.3.004

\section{Conclusion}

The exploration on the cloud computing done by surveying through different research works proceeded with the cloud based on its key characteristics, the service provisioning and the deployment models, helps in the understanding of the cloud attributes and the reason for its increased popularity. The capability of the cloud to provide its service irrespective of time, person and place makes it ubiquitous, this ubiquitous nature enables the cloud to become the promising paradigm for a wide range of applications such as, heath, national security, education, industry, banking etc. The paper reviewing the ubiquity of cloud, proceeds with the usefulness of the cloud services in the personal mobile network, by presenting the remedies of the personal mobile network insufficiencies from the various research surveyed based on the cloud services. This review would enable a personal mobile network in future to be developed with the enhanced performance by clubbing with the cloud services. In future the review presented would be utilized in developing the personal mobile network that is efficient in terms storage, processing capabilities and security.

\section{References}

[1] Khan, Asharul Islam, and Ali Al-Badi. "Ubiquitous Application Testing on Cloud." In 2018 International Conference on Smart Computing and Electronic Enterprise (ICSCEE), pp. 1-4. IEEE, 2018.

[2] Senyo, Prince Kwame, Erasmus Addae, and Richard Boateng. "Cloud computing research: A review of research themes, frameworks, methods and future research directions." International Journal of Information Management 38, no. 1 (2018): 128-139.

[3] Younas, Muhammad, Dayang NA Jawawi, Imran Ghani, Terrence Fries, and Rafaqut Kazmi. "Agile development in the cloud computing environment: A systematic review." Information and Software Technology 103 (2018): 142-158.

[4] De la Prieta, Fernando, Sara Rodríguez-González, Pablo Chamoso, Juan Manuel Corchado, and Javier Bajo. "Survey of agent-based cloud computing applications." Future Generation Computer Systems 100 (2019): 223-236.

[5] Rath, Mamata. "Resource provision and QoS support with added security for client side applications in cloud computing." International Journal of Information Technology 11, no. 2 (2019): 357-364.

[6] Somula, Ramasubbareddy, Chunduru Anilkumar, B. Venkatesh, Aravind Karrothu, CS Pavan Kumar, and R. Sasikala. "Cloudlet services for healthcare applications in mobile cloud computing." In Proceedings of the 2nd International Conference on Data Engineering and Communication Technology, pp. 535-543. Springer, Singapore, 2019. 
J. Sustain. Wireless Syst.

Vol.01/ No. 03

Pages: 176-188

http://irojournals.com/irosws/

DOI: https://doi.org/10.36548/jsws.2019.3.004

[7] Alkhalaileh, Mohammad, Rodrigo N. Calheiros, Quang Vinh Nguyen, and Bahman Javadi. "Dynamic Resource Allocation in Hybrid Mobile Cloud Computing for Data-Intensive Applications." In International Conference on Green, Pervasive, and Cloud Computing, pp. 176-191. Springer, Cham, 2019.

[8] Stergiou, Christos, Kostas E. Psannis, Byung-Gyu Kim, and Brij Gupta. "Secure integration of IoT and cloud computing." Future Generation Computer Systems 78 (2018): 964-975.

[9] Gai, Keke, Meikang Qiu, and Hui Zhao. "Energy-aware task assignment for mobile cyber-enabled applications in heterogeneous cloud computing." Journal of Parallel and Distributed Computing 111 (2018): 126-135.

[10] Elhoseny, Mohamed, Ahmed Abdelaziz, Ahmed S. Salama, Alaa Mohamed Riad, Khan Muhammad, and Arun Kumar Sangaiah. "A hybrid model of internet of things and cloud computing to manage big data in health services applications." Future generation computer systems 86 (2018): 13831394.

[11] Kaur, Harmanjeet, Neeraj Kumar, and Shalini Batra. "ClaMPP: a cloud-based multi-party privacy preserving classification scheme for distributed applications." The Journal of Supercomputing 75, no. 6 (2019): 3046-3075.

[12] Mishra, Bhabani Shankar Prasad, Himansu Das, Satchidananda Dehuri, and Alok Kumar Jagadev, eds. Cloud Computing for Optimization: Foundations, Applications, and Challenges. Springer International Publishing, 2018.

[13] Boukerche, Azzedine, and E. Robson. "Vehicular cloud computing: Architectures, applications, and mobility." Computer networks 135 (2018): 171-189.

[14] Colman-Meixner, Carlos, Chris Develder, Massimo Tornatore, and Biswanath Mukherjee. "A survey on resiliency techniques in cloud computing infrastructures and applications." IEEE Communications Surveys \& Tutorials 18, no. 3 (2016): 2244-2281.

[15] Alsmirat, Mohammad A., Yaser Jararweh, Islam Obaidat, and Brij B. Gupta. "Internet of surveillance: a cloud supported large-scale wireless surveillance system." The Journal of Supercomputing 73, no. 3 (2017): 973-992.

[16] Suciu, George, Alexandru Vulpe, Simona Halunga, Octavian Fratu, Gyorgy Todoran, and Victor Suciu. "Smart cities built on resilient cloud computing and secure internet of things." In 2013 19th International Conference on Control Systems and Computer Science, pp. 513-518. IEEE, 2013.

[17] Pfarr, Florian, Thomas Buckel, and Axel Winkelmann. "Cloud Computing Data Protection--A Literature Review and Analysis." In 2014 47th Hawaii International Conference on System Sciences, pp. 5018-5027. IEEE, 2014.

[18] Aceto, Giuseppe, Alessio Botta, Walter De Donato, and Antonio Pescapè. "Cloud monitoring: A survey." Computer Networks 57, no. 9 (2013): 2093-2115. 
J. Sustain. Wireless Syst.

Vol.01/ No. 03

Pages: 176-188

http://irojournals.com/irosws/

DOI: https://doi.org/10.36548/jsws.2019.3.004

[19] Koubâa, Anis, Basit Qureshi, Mohamed-Foued Sriti, Azza Allouch, Yasir Javed, Maram Alajlan, Omar Cheikhrouhou, Mohamed Khalgui, and Eduardo Tovar. "Dronemap planner: A service-oriented cloud-based management system for the internet-of-drones." Ad Hoc Networks 86 (2019): 46-62

[20] .Varadarajan, Vijayakumar, Venkataraman Neelanarayanan, Ron Doyle, Imad Fakhri Al-Shaikhli, and Sven Groppe. "Emerging Solutions in Big Data and Cloud Technologies for Mobile Networks." Mobile Networks and Applications 24, no. 3 (2019): 1015-1017.

[21] Lee, Woonghee, and Hwangnam Kim. "Heterogeneous cloud storage system for privacy." In 2014 Sixth International Conference on Ubiquitous and Future Networks (ICUFN), pp. 193-198. IEEE, 2014.

[22] Mohammad, Ashiquee Rasool, Khalid Mohiuddin, Mohammed Irfan, and Mohammed Moizuddin. "Cloud the mainstay: growth of social networks in mobile environment." In 2013 International Conference on Cloud \& Ubiquitous Computing \& Emerging Technologies, pp. 14-19. IEEE, 2013.

[23] Cheng, Qiong, and Chong-Zhi Gao. "A cloud aided privacy-preserving profile matching scheme in mobile social networks." In 2017 IEEE International Conference on Computational Science and Engineering (CSE) and IEEE International Conference on Embedded and Ubiquitous Computing (EUC), vol. 2, pp. 195-198. IEEE, 2017.

[24] Nagata, Masaki, Yusuke Abe, Nobuyuki Takanashi, Misato Fukui, Kunihiro Yamazaki, and Takahiro Hasegawa. "Development of Secure Safety Confirmation System Using Virtual Private Cloud." In 2018 Eleventh International Conference on Mobile Computing and Ubiquitous Network (ICMU), pp. 16. IEEE, 2018.

[25] Toosi, Adel Nadjaran, Jungmin Son, Qinghua Chi, and Rajkumar Buyya. "Elasticsfc: Auto-scaling techniques for elastic service function chaining in network functions virtualization-based clouds." Journal of Systems and Software (2019).

[26] Hasan, Ragib, and Rasib Khan. "A cloud you can wear: Towards a mobile and wearable personal cloud." In 2016 IEEE 40th Annual Computer Software and Applications Conference (COMPSAC), vol. 1, pp. 823-828. IEEE, 2016.

[27] Lounis, Ahmed, Abdelkrim Hadjidj, Abdelmadjid Bouabdallah, and Yacine Challal. "Healing on the cloud: Secure cloud architecture for medical wireless sensor networks." Future Generation Computer Systems 55 (2016): 266-277.

[28] AlZain, Mohammed A., Eric Pardede, Ben Soh, and James A. Thom. "Cloud computing security: from single to multi-clouds." In 2012 45th Hawaii International Conference on System Sciences, pp. 54905499. IEEE, 2012.

[29] Shen, Jian, Ziyuan Gui, Sai Ji, Jun Shen, Haowen Tan, and Yi Tang. "Cloud-aided lightweight certificateless authentication protocol with anonymity for wireless body area networks." Journal of Network and Computer Applications 106 (2018): 117-123. 
J. Sustain. Wireless Syst.

Vol.01/ No. 03

Pages: 176-188

http://irojournals.com/irosws/

DOI: https://doi.org/10.36548/jsws.2019.3.004

[30] Meneses, Flávio, Carlos Guimarães, Tiago Magalhães, Diogo Gomes, Daniel Corujo, and Rui L. Aguiar. "Deviceless Communications: Cloud-Based Communications for Heterogeneous Networks." Wireless Personal Communications 100, no. 1 (2018): 25-46.

[31] Zheng, Xiaochen, Raghava Rao Mukkamala, Ravi Vatrapu, and Joaqun Ordieres-Mere. "Blockchain-based personal health data sharing system using cloud storage." In 2018 IEEE 20th International Conference on e-Health Networking, Applications and Services (Healthcom), pp. 1-6. IEEE, 2018.

[32] Todorov, Milen Hrabarov, Boyanka Marinova Nikolova, and Georgi Todorov Nikolov. "Cloudmanaged ZigBee sensor networks." In 2016 XXV International Scientific Conference Electronics (ET), pp. 1-4. IEEE, 2016.

[33] Anwar, Ali, Anca Sailer, Andrzej Kochut, Charles O. Schulz, Alla Segal, and Ali R. Butt. "Costaware cloud metering with scalable service management infrastructure." In 2015 IEEE 8th International Conference on Cloud Computing, pp. 285-292. IEEE, 2015.

[34] Sharma, Yogesh, Bahman Javadi, Weisheng Si, and Daniel Sun. "Reliability and energy efficiency in cloud computing systems: Survey and taxonomy." Journal of Network and Computer Applications 74 (2016): 66-85.

[35] Leung, Victor CM, Roy Xiaorong Lai, Min Chen, and Jiafu Wan. "Cloud computing." (2010).

[36] Barika, M. U. T. A. Z., S. A. U. R. A. B. H. Garg, ALBERT Y. Zomaya, L. I. Z. H. E. Wang, A. van Moorsel, and R. A. J. I. V. Ranjan. "Orchestrating big data analysis workflows in the cloud: research challenges, survey, and future directions." ACM Computing Surveys (2019): 1-37.

[37] Manvi, Sunilkumar S., and Gopal Krishna Shyam. "Resource management for Infrastructure as a Service (IaaS) in cloud computing: A survey." Journal of network and computer applications 41 (2014): 424-440. Dick Epema. "Performance analysis of cloud computing services for many-tasks scientific computing." IEEE Transactions on Parallel and Distributed systems 22, no. 6 (2011): 931-945.

Ahmed, Ejaz, Adnan Akhunzada, Md Whaiduzzaman, Abdullah Gani, Siti Hafizah Ab Hamid, and Rajkumar Buyya. "Network-centric performance analysis of runtime application migration in mobile cloud computing." Simulation Modelling Practice and Theory 50 (2015): 42-56. 
J. Sustain. Wireless Syst.

Vol.01/ No. 03

Pages: 176-188

http://irojournals.com/irosws/

DOI: https://doi.org/10.36548/jsws.2019.3.004

[40] Coutinho, Emanuel Ferreira, Flávio Rubens de Carvalho Sousa, Paulo Antonio Leal Rego, Danielo Gonçalves Gomes, and José Neuman de Souza. "Elasticity in cloud computing: a survey." annals of telecommunications-annales des télécommunications 70, no. 7-8 (2015): 289-309.

[41] Qiu, Tie, Ning Chen, Keqiu Li, Daji Qiao, and Zhangjie Fu. "Heterogeneous ad hoc networks: Architectures, advances and challenges." Ad Hoc Networks 55 (2017): 143-152.

[42]

Sakr, Sherif, Anna Liu, Daniel M. Batista, and Mohammad Alomari. "A survey of large scale data management approaches in cloud environments." IEEE Communications Surveys \& Tutorials 13, no. 3 (2011): 311-336..

[43] Yang, Heng-Li, and Shiang-Lin Lin. "User continuance intention to use cloud storage service." Computers in Human Behavior 52 (2015): 219-232.

[44] Khan, Samiya, Kashish Ara Shakil, and Mansaf Alam. "Cloud-based big data analytics—a survey of current research and future directions." In Big Data Analytics, pp. 595-604. Springer, Singapore, 2018.

[45] Goode, Sigi. "A note on service switching: Evidence from cloud storage services." Services Marketing Quarterly 36, no. 2 (2015): 153-172.

[46] Dinh, Hoang T., Chonho Lee, Dusit Niyato, and Ping Wang. "A survey of mobile cloud computing: architecture, applications, and approaches." Wireless communications and mobile computing 13, no. 18 (2013): 1587-1611.

[47] Qiu, Tie, Ning Chen, Keqiu Li, Daji Qiao, and Zhangjie Fu. "Heterogeneous ad hoc networks: Architectures, advances and challenges." Ad Hoc Networks 55 (2017): 143-152.

[48] Hsu, Pei-Fang, Soumya Ray, and Yu-Yu Li-Hsieh. "Examining cloud computing adoption intention, pricing mechanism, and deployment model." International Journal of Information Management 34, no. 4 (2014): 474-488.

[49] Aminzadeh, Nazanin, Zohreh Sanaei, and Siti Hafizah Ab Hamid. "Mobile storage augmentation in mobile cloud computing: Taxonomy, approaches, and open issues." Simulation Modelling Practice and Theory 50 (2015): 96-108.

[50] Costa, Paulo, Ricardo Montenegro, Teresa Pereira, and Pedro Pinto. "The Security Challenges Emerging from the Technological Developments." Mobile Networks and Applications (2019): 1-6. 